Guy and Ferrier, I cannot find a single paragraph upon the subject. In mentioning the symptoms, I find that I have omitted to allude to one-that is, the diabetic halitus, upon the absence of which in acetonæmia Dr. Southey has somewhat insisted. In E. R-'s case it was also quite absent. Newtown, Montgomeryshire.

\section{POISONING BY LEAD DICHROMATE.}

\author{
By R. C. SMITH, M.D., B.Sc. (Public Health) EdIN.
}

ON February 12th, 1881, Mrs. B-, aged thirty, a weaver in a cotton-mill, came to me for advice and treatment. She had been unable to follow her work for the previons six weeks, and was suffering from great weakness, wandering pains in her limbs, and anæmia. Her gums showed wellmarked signs of lead poisoning; there was no albumen in her urine. She attributed her illness to the inhalation of a yellow dust that was given off from the yarn in the process of weaving an orange-coloured cloth. She had always enjoyed good health before being engaged at this class of work. She gave as a reason that it was the coloured dust (lead dichromate) which had made her ill ; that her fellowworkers when engaged at the same kind of work sooner or later sickened, and that there were many others at home ill from the same cause.

Mary $\mathrm{C}-$, also a weaver at the same mill, applied for advice a few days after Mrs, $B$ - and had like her been engaged as a weaver of orange yarn. The blue line was very distinct. Her breath was offensive, and the skin and conjunctivæ of a distinctly yellow colour. There was no albumen or bile in the urine, nor had she any tenderness over the liver. She suffered from tormina and wandering pains over the body, and was very costive. Under treatment the yellowness of skin passed away, but the blue line remained long after other symptoms of lead poisoning had disappeared.

Jane C- sister of the above, was visited by me at her own home on the same day. I found her also affected with lead poisoning. She appeared to be, at first sight, suffering from an acute attack of jaundice. Her skin and conjunctivæ were intensely yellow. There was obstinate sickness and purging of durk sap-green motions, probably stained with chromic oxide. The urine contained albumen with a trace of chromium, but no bile or lead. This patient recnvered with great difficulty; the staining of the tissues, sickness, and purging ceasing first, but the blue line is still present.

The above are types of cases that were of constant occurrence nine montbs ago, in the practices of medical men in the neighbourhood of the mill in question. I had eight cases at once under my treatment from the same mill for this peculiar form of lead poisoning. Another medical man has had twenty, and $a$ third has had from thirty to forty similar cases in all under observation. One of the mill hands, under the care of a fourth medical man, dying from lead poisoning resulted in an inquest, when at the postmortem ordered by the coroner the surgeon found distinct traces of lead in the liver. Public opinion having been thus drawn to the dangerous nature of the work, pressure was brought to bear on the employers, who have since then caused the yarn to be more carefully dyed and prepared before being woven. They have also insisted on the winders and weavers wearing a muslin respirator over the mouth and nose when at work, and the use of hooks instead of sucking with the month the yarn through the eye of the shuttle. By these precautions having been rigorously carried out, the operatives, though still weaving chromes, no longer suffer from lead poisoning. A microscopic examination of the fibres of the cloth made from the yarn which I obtained from the manufacturers, shows minute crystals of the orange chrome adhering to the outside of the filaments, as well as others still more minute within the tubule and in the interspaces of the cortex. The crystals on the surface are easily washed away by trituration with water and settle at the bottom of the washing, whence, if collected and fused with nitre and carbonate of soda, the characteristically yellow chromate of soda is produced. Ammonium sulphide blackens the crystals at once.

In the cases which $I$ have observed, the yellowness of the skin is the first symptom to disappear, and the blue gums the last; chromium exists in the urine, and most probably in the fæces. I therefore conclude that after adsorption the dichromate undergoes decomposition in the blood, the lead being fixed in the tissua, whilst the chromic acid combines with soda, a compound which is intensely yellow and stains the liquor sanguinis and skin for a time, and finally leares the body by the liver and kidneys. Ard wick.

\section{CASE OF EXTERNAL BILIARY FISTULA.}

\section{BY J. MACKENZIE BOOTH, M.A., M.B. ABERD.}

THE following case, which recently came under my observation, is, by reason of its somewhat rare occurrence, worthy of being recorded.

The patient, a laìy aged seventy-seven, had for ten years suffered from well-marked attacks of hepatic colic; and, until three years ago, these occurred at intervals of a few weeks. Towards the end of September, 1879, I attended her during an unusually severe attack, which lasted for several days. The attack was accompanied by retching and jaundice, but, though the stools were repeatedly searched, no gall-stones were found. Since then she has been entirely free from these seizures, only complaining from time to time of slight pain or uneasiness in the right hypochondrium. In June, 1881, a painful swelling appeared on the right side, which remained some time before it became red and burst, giving exit to a scanty yellowish discharce. Save its persistence, she noticed nothing unusual, until, one night towards the end of December, while prepa "ing to retire, she discovered a hard black point protruding fiom the orifice of the wound. As it hurt her on being touched, she had recourse to a hair-pin, with which, after one or two vain attempts, she succeeded in dislodging a hard black body ahout the size of a large pea. Next day two concretions of a similar size were passed.

On calling, I found the objects to be medium-sized gallstones, about a quarter of an inch in diameter. On examination of the abdomen, a depression of the integument was noted round a small wound about a quarter of an inch in breadth, situated on the right side, nearly midway between the umbilicus and the crest of the ilium. A thick indurated band of about an inch in breadth could be felt deeply through the abdominal wall, passing up towards the gallbladder until it was lost over the site of that organ at the margin of the costal cartilage. A scanty sero-purulent discharge slightly tinged with bile continued to ooze from the opening. Several more gall-stones have since been extruded, varying in size from that of a millet-seed to that of a pea. Further than this there is nothing wortby of remark, save that the formation of the fistula and the appearance of the calculi explain the abrupt leave-taking (now three years since) of the patient's periodic and painful visitant.

Aberdeen.

\section{NOTE ON THE}

\section{TREATMENT OF ACUTE TONSILLITIS BY} SALICYLATE OF SODA.

BY JOSEPH W. HUNT, M.D., B.S. LOND.

WHILE the treatment of rheumatic fever by salicin and salicylate of soda is under discussion in the pages of THE LANCET it may be well to notice the effect of the same drugs in an allied disease. The close connexion which has long been recognised between rheumatism and certain forms of tonsillitis induced me to try this remedy, and the results have been most favourable. In my hands it has acted almost as a specific in acute tonsillitis. Provided that there is no actual formation of pus, most decided relief is afforded in about twenty-four hours-i.e., the swelling and angry-looking condition of the tonsils are reduced, pain diminished, and the patient can swallow with comfort, while the temperature becomes normal and the pulse is reduced in frequency and improved in quality. Since I have used this drug I have had no single case go on to suppuration; nay, more, where it has appeared, from the state of the tonsils and the brawny and infiltrated condition of neighbouring parts, 
that suppuration must ensue, it has been arrestel by this treatment. The doses used have been fifteen grains every four hours for an adult, and about ten grains every four hours for a child. I have met with no unpleasant symptoms from its use, beyond a little tinnitus and occasional vertigo. When the brunt of the attack has fallen upon one tonsil, a relapse in the other, when the salicylate has been discontinued, is not uncommon, but thi speedily yields to the same treatment Oue or two medical friends, who have used the salicylate at my suggestion, have expressed themselves in equally favourable terms. As one said, "they get well too quiukly."

Dalston, E.

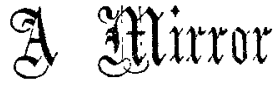

\section{oF}

\section{HOSPITAL PRACTICE, BRITISH AND FOREIGN.}

Nulla autem est alia pro certo noscendi via, nisi quamplurimas et morborum et dissectionum historias, tum aliorum tum proprias collectas habere, et inter se comparare.-Mongagrr De Sed. et Caus. Morb., lib. iv. Pronemium.

\section{CHARING-CROSS HOSPITAL.}

TUMOUR OF TESTIS ; EXTIRPATION ; RECOVERT; REMARKS. (Under the care of Mr. Bellamy.)

For the notes of the following case we are indebted to Mr. Dodson, dresser.

T. P-C, aged thirty-three, a horsekeeper, married, was admitted to the Albert Edward ward on Dec. 12th, 1881. Eighteen months before his left testicle began gradually to enlarge and continued doing so until a month before admis sion, when it had attained the size of a cocoa-nut. It then enlarged very rapidly and became softer. From the first the testicle was the seat of sharp, stabbing, lancinating pains, the intervals between the sharp pains being occupied by a heavy, wearying, aching pain. He had never, so far as he could remember, received a blow on the testicle and could not account in any way for its enlargement. He had always been fairly healthy, and had never had syphilis or gonorrhoea, and had always led a steady life. His father was alive and healthy; his mother died of "the rupture of a bloodvessel." No history of carcinoma, phthisis, or other disease in the family.

Of late the patient had been losing flesh, though, on admission, he looked fairly healthy. His left testis was enlarged to about the size of an ostrich's egg, the growth measuring eleven inches and three-quarters in circumference. The enlargement was slightly irregular, and preseuted points of different consistence on its surface, in some parts being quite hard, in others soft and semi-fluctuating. It was exceedingly heavy, and the cord was enlarged and tender to the touch. The iliac glands along the vessels did not appear to be affected. The scrotal veins were enlarged and tortuous, and the skin in places was shiny and smooth. The patient was not cachectic

On Dec 12th Mr. Bellamy selected one of the fluctuating points and introduced a trocar and canvula, but with negative results. On the 15th, the patient beiug under the influence of ether, Mr. Bellamy removed the testicle by an incision extending almost from the internal abdomind ring to the lowest part of the scrotum on the left side. The scrotal tissues, which were very adherent to the tumour, were carefully dissected off, and the cord septrated from the surrounding parts. A strong ligature was passed round the cord, and then while an assistant pulled on this ligature a second thread was passed through the cord a little higher up. The testicle was removed by dividing the cord between the two ligatures. As, however, the disease ex. tended quite up to the point of ligature on the cord, Mr. Bellamy deemed it advisable to apply another higher up. This was done, after eslarging the incision quite to the internal abdominal ring. The tumour was now removed, and the ends of the ligature left out of the wound. During the operation there was considerable hæmorrhage from small vessels, which were tied. The scrotum (a portion of which being apparently implicated in the disease was removed) was washed uut thoroughly with a solution of carbolic acid ( 1 in 20 ), a drainage-tube inserted, and the edges cf the wound brought together with wire sutures, and dressed with curbolic lutiun. - 16th: Dressed to-day; wound looks well. Temperature $101 \cdot 1^{\circ}$. Passed a fairly good night; not in much pain.-17h: Dressed; pain decreasing. Muruing temperature, $1002^{\circ}$; erening, $102^{\circ}$. Being troubled with consipation, he was ordered a pill composed of ten grains of ealomel with colocyuth at bedtime.-18th: Does uot fetl quite so well to-day; two or three of the sutures cansiug irritation were removed this moruing; edges of wound have a tendency to slough. Morning temperature, $102^{\circ}$; evening, $1024^{\circ}$.-19ih: Linseed poultices applied to remove slough; feels better. Morning temperature, $1008^{\circ}$; evening, $1015^{\circ}$.-21:t: The edges of the nound now look much better; the poultices were discontinued; dressed with (arbolic lotion. Morning temperature, $100^{\circ}$; evening, $100^{\circ}$.25 th: Going on well; wound healing in centre; slight purulent discharge from upper part. Moruing temperature, $98 \cdot 2^{\circ}$; evening, $100^{\circ}$. -28 th : Ligature of cord cause away this morning with dressing; pain entirtly ceased. Morning temperature, $98^{\circ} 4^{\circ}$; evening, $99^{\circ}$. - 31st : Wound healing nicely; discharge gradually beenming less; patient lonks and feels much better. Moruing temperature, $99^{\circ}$; evening, $99^{\circ}$. Jan. 5th, 1882: Guing on well. Morning temperature, $98^{\circ}$; eveuing, 98. - 11th : Carbolic dressing changed for more stimulating red lotion; wound has healed, except for a tiiangular space at the rout of penis. -15 th: Triangular space is now covered with healthy granulations; a small lump about the size of an :1mond can now be felt beneath the skin of the scrotum; it gives no pain on pressure.21 st : Lump incressiog slowly, but still painless. Temperature normal.

A microscopical examination of the tumour showed it to be a round-celled sarcoma.

Remarks.-Mr. Bellamy remarked, in the course of some clinical observations on disease of the testicle, that in this instance the removal of the gland was not so eary as is generally the case. In the first place, the scrotal tissues were firmly adherent to the anteriur surface of the tumour, and therefore a departure from the ordinary linear incision was nece:sary, in the form of an ovoid one, clear of such adberence. After isolation the mass was fuund to be immensely heary (a factor in diagnosing), and the cord had to be exposed by free incision of the abdominal parietes. The small intestine bulged freely on either side of the cord, and, of course, the greater peritoneal sac was opened. $\mathrm{Mr}$. Bellamy thinks it better, if possible, to treat the cord in castration as a stump of an amputation, and to tie each vessel as it bleeds, the control of the cord being maintained by vulsellum forceps, a general ligature of all the tissues frequently giving rise to a troublesome neuralgia. With regard to "palpation" of the iliac region, Mr. Bellamy observed how frequently this important aid to diagnosis of testicular growths was disregarded, and an operation either decided upun or given up on mere inspection. No spray was used, but the exposed gut ard cord were well treated with 1 in 20 carbolic solution, and the temperature chart never went abuve $102^{\circ}$.

\section{GLASGOW ROYAL INFIRMARY}

\section{IYTERYITTENT FEVER TREATED BY HYPODERMIO} INJECTIONS OF QUININE

(Under the care of Professor Charteris.)

Fon the following notes we are indebted to Dr. P. A. Swith, house-pbysician.

Peter Q- a sailor, aged thitty-two, was admitted on the 13th December, 1881. He stated that his present illness (fever) commenced three mouths befure, when he was in the East India ports, and that it came on suddenly with cold and subsequent shivering, which contivued for about a quarter of an hour, and was immediately followed by a stage of fever which lasted for a couple of hours. After the expiry of this period there followed a profuse perspiration, "his whole budy being bathed in swea:" Afrerwaids the patient felt quite well, but on the following day at the same time there supervened the same sequelæe of (1) cold, (2) hot, and (3) sweating stage. On adwission, in addition to these srmptoms of tevir, he showed traces of scurvy, which he said 